\title{
PERSAINGAN ISLAM DAN KRISTEN DI KOTA SOLO: SEBUAH TINJAUAN SEJARAH
}

\author{
Adif Fahrizal Arifyadiputra* \\ Program Studi Sejarah Peradaban Islam IAIN Salatiga, Indonesia
}

\begin{tabular}{|c|c|}
\hline Abstract & Abstrak \\
\hline $\begin{array}{l}\text { The main problem studied in this study is how the } \\
\text { process of Islamization and Christianization took place } \\
\text { in Surakarta in the New Order, who are the actors, and } \\
\text { what the impact this process. Also how identities take } \\
\text { root by this process gave a way for the competition and } \\
\text { suspicion between those communities. This article } \\
\text { concluded that the socio-political context surrounding } \\
\text { Islamization and Christianization in Surakarta and } \\
\text { social background of the actors involved in this process } \\
\text { have great influence on religious identities that } \\
\text { developed and competed in Surakarta. } \\
\text { Keywords: Islamization, Christianization, competition, } \\
\text { identity. }\end{array}$ & $\begin{array}{l}\text { Permasalahan pokok yang dikaji penelitian ini adalah } \\
\text { bagaimana proses Islamisasi dan Kristenisasi } \\
\text { berlangsung di Surakarta pada masa Orde Baru, siapa } \\
\text { saja aktor-aktornya, dan bagaimana dampak dari } \\
\text { proses tersebut. Lalu bagaimana identitas yang lahir } \\
\text { dari proses itu melahirkan persaingan dan kecurigaan } \\
\text { antar komunitas. Artikel ini ditulis berdasarkan } \\
\text { penelitian menggunakan metode sejarah. Artikel ini } \\
\text { mengambil kesimpulan bahwa konteks sosial-politik } \\
\text { yang melingkupi Islamisasi dan Kristenisasi di Surakarta } \\
\text { dan latar belakang sosial para aktoryang terlibat dalam } \\
\text { proses ini berpengaruh besar pada identitas } \\
\text { keberagamaan yang berkembang dan saling } \\
\text { berkontestasi di Surakarta. }\end{array}$ \\
\hline
\end{tabular}

\section{PENDAHULUAN}

Belum lama ini kota Solo dihebohkan oleh demonstrasi dari sekelompok orang yang mengatasnamakan umat Islam Surakarta memrotes desain jalan di koridor Jalan Jenderal Sudirman - salah satu jalan utama di Solo - karena dianggap menyerupai simbol salib. ${ }^{1}$ Meskipun sudah ada bantahan bahwa desain tersebut bukan menggambarkan salib massa yang tergabung dalam Dewan Syariah Kota Surakarta (DSKS) dan Laskar Umat Islam Surakarta (LUIS) tetap bersikukuh bahwa desain itu adalah salib dan menuntut kepada pemerintah Kota Solo agar menghapusnya. ${ }^{2}$ Pemerintah kota akhirnya mengalah dan memutuskan menghapus desain tersebut. ${ }^{3}$

Peristiwa terbaru ini bukanlah kasus bernuansa sentimen agama yang pertama kalinya terjadi di Solo. Sebelumnya, pada 2015 sejumlah elemen Islam di Solo menggelar sebuah parade bertajuk "Parade Tauhid" di ruas jalan utama kota ini. ${ }^{4}$ Parade ini sendiri diadakan sebagai reaksi atas Parade Salib yang digelar umat Kristen di Solo pada peringatan Paskah di lokasi yang sama beberapa waktu sebelumnya. ${ }^{5}$

Timbulnya aksi-aksi bernuansa kontra-simbol-simbol Kristen oleh beberapa elemen Islam di Solo adalah cerminan perasaan terancam akan "Kristenisasi" dari sebagian umat Islam di Solo. Perasaan terancam ini tentu tidak lahir secara tiba-tiba melainkan akumulasi dari memori yang terbentuk lewat pengalaman sejarah umat Islam di kota ini. Tulisan ini mencoba mengupas akar historis timbulnya perasaan terancam sebagian kalangan Islam di Solo terhadap "Kristenisasi”.

*Correspondance Author: adiffahrizal@yahoo.com

Article History | Submitted: July 2, 2019 | Accepted: December 23, 2019 | Published: January 5, 2020

How to Cite (APA $6^{\text {th }}$ Edition style):

Arifyadiputra, A. F. (2020). Persaingan Islam dan Kristen di Kota Solo: Sebuah Tinjauan Sejarah. JUSPI (Jurnal Sejarah Peradaban Islam), 3(2), 142-157. 


\section{HASIL DAN PEMBAHASAN}

\section{Aktivisme Islam di Solo Masa Kolonial Belanda}

Terbentuknya organisasi SDI (Sarekat Dagang Islam) yang kemudian menjadi SI (Sarekat Islam) adalah tonggak penting bagi aktivisme Islam di kota Solo. Pada 9 November 1911 SDI berdiri dengan Samanhoedi sebagai ketuanya dan tak lama kemudian organisasi ini berganti nama menjadi SI. ${ }^{6}$ SI menjadi penting bukan hanya sebagai sebuah organisasi Islam tetapi juga sebagai sebuah gerakan yang memperjuangkan kepentingan masyarakat pribumi. Organisasi ini berhasil menarik tidak hanya kaum pedagang yang merupakan kelompok pendiri dan pendukung awalnya tetapi juga rakyat kebanyakan. Hanya saja dalam perkembangannya kemudian SI terpecah menjadi dua yang sedikit banyak mencerminkan polarisasi antara kaum pedagang dan rakyat jelata. Umumnya kaum pedagang membawa ideologi Islam yang dipertahankan oleh SI Putih sementara rakyat jelata banyak terserap ke dalam SI Merah yang berideologi komunis. Banyak di antara kaum pedagang yang tergabung dalam SI Putih bergabung juga dengan Muhammadiyah.

Cikal bakal Muhammadiyah di Surakarta adalah organisasi Sidik Amanah Tabligh Vathonah (SATV) yang berdiri tahun 1918.7 Organisasi ini didirikan oleh kaum Muslim reformis di kota Solo, di antaranya Haji Misbach - yang kelak dikenal pula sebagai seorang tokoh komunis. Pada 1922 SATV menyatakan dirinya sebagai Afdeling Surakarta dari Muhammadiyah. ${ }^{8}$ Segera sesudah berdiri di Solo, Muhammadiyah menjalankan aktivitas sosialnya di kota tersebut. Aktivitas sosial Muhammadiyah di Solo meliputi antara lain pendirian sekolah-sekolah, rumah yatim, dan klinik-klinik. ${ }^{9}$

Sementara itu, gerakan SI Merah adalah wujud lain dari gerakan Islam yang tumbuh di Solo pada awal abad ke-2o. Yang menarik dari gerakan ini adalah sintesis yang mereka lakukan antara Islam dengan komunisme. Tokoh utama SI Merah di Solo Haji Misbach memandang komunisme sesuai dengan Islam karena komunisme ingin menghapuskan penghisapan dan penindasan oleh sekelompok orang - yaitu para pemilik modal - terhadap sesama manusia, cita-cita komunisme ini sejalan dengan ajaran Islam yang menolak segala bentu kezaliman. Lebih jauh ia bahkan mengklaim bahwa orang Islam yang menolak komunisme sebagai orang Islam palsu. Di sisi lain, sebagimana dicatat Shiraishi, Misbach menyatakan bahwa orang komunis yang hendak melenyapkan agama Islam bukanlah seorang komunis sejati. ${ }^{10}$

Memasuki akhir dekade 1920-an dan dekade selanjutnya di Solo mulai muncul kesadaran akan pentingnya persatuan di antara sesama kaum Muslim, lepas dari sekatsekat organisasi yang sudah ada ketika itu. Kesadaran itu mewujud dalam bentuk kumpulan yang menamakan dirinya "Oemat Islam". Kumpulan ini muncul dalam momentum-momentum tertentu atau saat sedang hangatnya isu-isu tertentu. Salah satu isu yang menjadi perhatian adalah gencarnya misi Kristen di Surakarta. Sebagaimana dinyatakan Khadiq, tanggal 31 Maret 1933 misalnya, Oemat Islam mengadakan openbare vergadering untuk menyikapi masuknya propagandis Kristen di daerah ini. Rapat terbuka yang dihadiri kurang lebih 2000 orang ini menghadirkan dua orang pembicara yang menyatakan penolakan atas masuknya Kristen di wilayah 
pribumi. Rapat lalu memutuskan mengirim surat kepada pemerintah berisi pernyatan ketidaksetujuan atas hal tersebut."

\section{Aktivisme Islam di Solo Masa Jepang hingga Kemerdekaan Indonesia}

Kedatangan bala tentara Jepang membawa hikmah tersendiri bagi kalangan Islam tak terkecuali di Solo. Jepang memandang golongan Islam sebagai golongan yang paling anti-Barat dan karenanya merupakan kelompok yang paling tepat untuk diajak bekerjasama membantu Jepang dalam Perang Asia Timur Raya. MIAI (Majelis Islam A'la Indonesia) sebagai wadah gabungan organisasi-organisasi Islam di Hindia tidak dibubarkan sebagaimana organisasi-organisasi pergerakan lainnya melainkan menjadi mitra bagi pemerintah militer Jepang meskipun pada 1943 berganti nama menjadi Masyumi (Majelis Syuro Muslimin Indonesia). Tidak hanya itu, pemerintah militer Jepang juga mengizinkan golongan Islam memiliki pasukan paramiliternya sendiri yaitu Laskar Hizbullah.

Kebanyakan anggota Hizbullah adalah para pemuda yang berlatar belakang pendidikan pesantren dan madrasah. Dari Surakarta sebagian besar anggotanya berasal dari Madrasah Mambaoel Oeloem dan Pondok Pesantren Jamsaren serta pesantrenpesantren lainnya. ${ }^{12}$ Usai menjalani pelatihan kemiliteran para peserta dikukuhkan sebagai anggota Laskar Hizbullah dan kembali ke daerahnya masing-masing untuk membentuk Laskar Hizbullah di sana. Di Solo Laskar Hizbullah terbentuk pada bulan Juli 1945 dan menyelesaikan pelatihannya pada bulan Agustus. ${ }^{13}$

Arti penting pasukan Hizbullah dalam kaitannya dengan perkembangan Islam di Solo harus dilihat dalam konteks pergolakan politik pada masa awal kemerdekaan. Pada periode ini Islam tidak sekadar menjadi sebuah agama tetapi juga ideologi politik yang dipandang harus ikut memainkan peran dalam perjuangan kemerdekaan. Oleh karena perjuangan kemerdekaan ketika itu berwujud perang fisik maka jelas keberadaan pasukan militer Hizbullah menjadi penting sebagai representasi militer Islam dan di sini Hizbullah menjadi 'wakil Islam dan umat Islam' dalam kancah perjuangan mempertahankan kemerdekaan. Dalam kancah perjuangan ini konflik tidak hanya terjadi antara kubu republiken melawan Belanda tetapi juga antara sesama kaum Republiken sendiri yang berbeda ideologi. Bagaimana konflik antar sesama kaum Republiken yang berbeda ideologi itu terlihat dalam benturan antara Hizbullah dengan pasukan-pasukan militer berhaluan kiri.

Benturan tersebut adalah bagian dari konflik antara golongan Islam dan komunis yang dalam konteks lokal Jawa mewujud sebagai konflik antara kaum santri dan abangan. Di Solo dan sekitarnya konflik ini dimulai dengan aksi mogok buruh di Delanggu Klaten yang diorganisir BTI (Barisan Tani Indonesia) dan Sarbupri (Sarekat Buruh Perkebunan Republik Indonesia) - keduanya onderbouw PKI - tahun 1948. Aksi mogok ini ditentang oleh golongan Islam dan nasionalis sehingga terjadilah bentrokan antara massa buruh yang diorganisir PKI dengan golongan Islam dan nasionalis. ${ }^{14}$

Sebagaimana di daerah-daerah lainnya di Indonesia, pada tahun 1950-an Solo juga menjadi arena persaingan politik yang hangat antar berbagai kekuatan politik. PKI yang sempat tiarap setelah Pemberontakan Madiun tahun 1948 mengorganisir dirinya kembali dan mampu bangkit di Solo yang memang sudah menjadi basisnya sejak tahun 
1920-an. Di kota ini PKI bersaing sengit dengan kekuatan politik Islam yang diwakili Partai Masyumi. Persaingan sengit antara kaum komunis dan Islam tidak jarang terwujud dalam bentuk kekerasan. Pada tahun 1951-1952 Batalyon 426 Divisi Diponegoro yang beranggotakan para mantan Laskar Hizbullah Divisi Sunan Bonang melakukan disersi. Mereka bergabung dengan gerakan Darul Islam/Tentara Islam Indonesia (DI/TII) dan memberontak kepada pemerintah. Dari markasnya di Semarang mereka melakukan perjalanan gerilya sampai ke Keresidenan Surakarta. ${ }^{15}$ Dalam melancarkan aksinya tidak jarang Batalyon 426 menyasar orang-orang PKI. Mereka dikabarkan mendapat dukungan dari para tuan tanah santri untuk menghadapi kaum buruh tani yang banyak menjadi massa PKI. Sebagaimana disebutkan Van Dijk dan Al Chaidar dalam bukunya, sejumlah tokoh Islam di kota Solo juga diduga mendukung Batalyon 426 secara diam-diam. ${ }^{6}$ Pada akhirnya pemberontakan Batalyon 426 berhasil ditumpas oleh TNI AD akan tetapi hal ini tidak menyurutkan kekuatan Islam politik yang bergerak lewat jalur konstitusional dalam wadah Masyumi. Persaingan antar partai politik sendiri semakin memanas khususnya menjelang pemilu nasional yang pertama tahun 1955. Di Solo menjelang Pemilu 1955 kerap terjadi bentrokan baik besar maupun kecil antara massa Masyumi dengan PKI. Dalam Pemilu 1955 di Solo Masyumi meraih 13.733 suara atau 11,10 \% dari total jumlah suara sah. Masyumi kalah jauh dibanding PKI yang memperoleh 70.808 suara $(57,26 \%)$ dan PNI yang mendapat 37.144 suara (30 \%). Namun perolehan suara Masyumi masih lebih baik dibanding NU yang hanya memperoleh 1.998 suara $(1,61 \%) .{ }^{17}$

Setelah Masyumi bubar para aktivis Masyumi mengalihkan aktivitasnya dari politik praktis ke medan dakwah yang lebih luas. Setelah partai ini bubar para aktivisnya berkiprah di organisasi Islam yang sudah ada seperti Muhammadiyah, Al Irsyad, Al Islam dan sebagainya. Selain itu sebagian dari mereka mendirikan organisasi atau lembaga baru seperti Petapechut (Persatuan Tabligh dan Pelaksana Chutbah) dan PTDI (Perguruan Tinggi Dakwah Islam). Menurut salah seorang mantan aktivis Masyumi, aktivitas dakwah pada era Demokrasi Terpimpin tersebut juga memiliki dimensi politis yaitu untuk mengimbangi propaganda yang gencar dilakukan oleh PKI. Sebagai contoh, pendirian PTDI menurutnya adalah untuk mengimbangi PKI yang mendirikan Universitas Rakyat, yaitu lembaga pendidikan non-formal bagi masyarakat luas. Sebagaimana Universitas Rakyat, PTDI juga adalah lembaga pendidikan non-formal hanya saja dengan ajaran Islam sebagai muatan dasar pendidikannya. ${ }^{18}$

\section{Misi Kristen di Solo Masa Kolonial Belanda}

Perkembangan agama Kristen di kota Solo dimulai pada masa kolonial. Lahirnya komunitas Kristen pribumi di daerah ini tidak lain adalah buah dari usaha pendidikan dan kesehatan yang diselenggarakan zending dan misi seiring dengan proses modernisasi yang berlangsung di Solo pada awal abad ke-20. Menurut penuturan salah seorang zending bernama Wolterbeek, penyebaran Kristen di daerah Keresidenan Surakarta awalnya tidak berjalan mulus. Pada 1891 dua badan zending dari Belanda NGZV (Nederlandsche Gereformeerde Zendeling Vereeniging) dan NZV (Nederlandsche Zendeling Vereeniging) mengajukan permohonan izin pekabaran Injil di Surakarta tetapi ditolak oleh pemerintah kolonial. Permohonan izin pendirian rumah sakit zending juga ditolak. Namun demikian lewat kebaktian keluarga, seorang dokter zending dr. J.G. Scheurer berhasil menarik minat beberapa orang Jawa yang 
diundangnya untuk menjadi Kristen. Akibat tindakannya ini dr. Scheurer terpaksa harus meninggalkan Solo. ${ }^{19}$ Hal tersebut menunjukkan ketatnya pemerintah kolonial memberlakukan larangan pekabaran Injil di Surakarta.

Larangan pemerintah kolonial terhadap pekabaran Injil di Surakarta erat kaitannya dengan kedudukan Surakarta sebagai daerah Vorstenlanden yang memiliki kekuasaan tersendiri di bawah penguasa pribumi yaitu Kasunanan dan Mangkunegaran sementara baik Sunan maupun Adipati Mangkunegaran dipandang bukan hanya sebagai pemimpin politik tetapi juga kepala agama Islam. Dalam pandangan pemerintah kolonial memperbolehkan penyebaran Kristen di daerah kekuasaan pribumi yang penguasanya adalah pemimpin politik sekaligus kepala agama Islam hanya akan menimbulkan masalah belaka. Walaupun demikian Sunan sendiri secara pribadi sesungguhnya tidak berkeberatan dengan aktivitas zending dan tidak memusuhi agama Kristen. Hanya saja sebagai panatagama Sunan berkeberatan jika rakyatnya memeluk agama di luar Islam. ${ }^{20}$

Larangan pekabaran Injil dan pendirian gereja Kristen untuk pribumi di Surakarta akhirnya dicabut tahun 1910 pada masa pemerintahan Gubernur Jenderal A.W.F. Idenburg (1909-1916). ${ }^{21}$ Pada masa itu usaha pekabaran Injil di Solo dipimpin oleh Pdt. D. Bakker. Aktivitas zending di Solo diawali dengan penyediaan layanan pendidikan berupa sekolah. Pada mulanya sesuai perintah Residen Surakarta sekolah tersebut hanya diperuntukkan bagi anak-anak yang orangtuanya beragama Kristen dan dilarang bagi anak-anak yang orangtuanya beragama Islam. Akan tetapi kabarnya ternyata banyak orang Islam yang memaksa agar anaknya diterima di sekolah zending itu. Inilah kemudian yang mendorong Bakker memohon izin kepada Gubernur Jendaral Idenburg yang berbuah pencabutan larangan pekabaran Injil di Surakarta sebagaimana disebutkan di atas. ${ }^{22}$

Sementara itu Katolik mulai masuk di Solo pada 1918 ditandai dengan berdirinya Gereja Santo Antonius di Purbayan. Tiga tahun kemudian HIS Katolik didirikan di Purbayan dengan seorang pribumi bernama Soemadisastra sebagai kepala sekolahnya. Pada tahun yang sama, tepatnya tanggal 4 Juli 1921 HIS Kanisius didirikan di Sosronegaran dengan Pastor van Dresiche sebagai guru agama dan budi pekertinya. Tahun 1922 HIS Kanisius dipindah ke Purbayan dikepalai H.I.W. Wormer. Mulai tahun itu sekolah-sekolah Kanisius didirikan di berbagai penjuru kota Solo mulai dari Semanggi Lor, Sorogenen, Pucangsawit, Purwoprajan, Kerten, dan Bromantakan. Sekolah-sekolah Kanisius ini mendapat subsidi dan kemudahan dari pemerintah kolonial dan pada mulanya bersifat netral agama. Para muridnya yang kebanyakan pribumi dan non-Katolik bebas memilih untuk mengikuti pelajaran agama Katolik atau tidak akan tetapi dalam perkembangannya pelajaran katekismus dimasukkan dalam kurikulum sekolah. Bahasa pengantar di sekolah-sekolah Kanisius adalah bahasa Belanda akan tetapi disisipkan pula bahasa Melayu. Kebijakan dalam organisasi dan kepengurusan baik pengelolaan gedung sekolah maupun pengangkatan guru ditangani langsung oleh para pastor Ordo Yesuit. Di samping para pastor Yesuit bruder-bruder dari FIC (Familar Immaculata Congregasi) juga terlibat menangani sekolah. Selain sekolah-sekolah formal Misi Katolik di Solo juga membuka sekolah-sekolah kejuruan. Sekolah-sekolah ini ditangani oleh para suster dari Ordo Fransiskan yang memulai karyanya di Solo sejak 1925. Sekolah-sekolah kejuruan ini hanya menerima murid 
perempuan dengan kurikulum khusus keterampilan untuk perempuan. ${ }^{23}$ Sekolahsekolah Katolik di Solo - seperti halnya di daerah lain - memiliki reputasi yang bagus. Banyak di antara kaum priayi yang memasukkan anak-anaknya ke sekolah Katolik tak terkecuali Sunan Paku Buwono X sendiri. ${ }^{24}$

Dalam waktu singkat pertumbuhan pemeluk Kristen di Solo maju pesat. Pada 1918 warga jemaat Gereformeerd di Solo sudah berjumlah 228 orang, meliputi orang Jawa dan Cina. Seiring bertambahnya jumlah pemeluk Kristen, mulai dilakukan pemisahan kelompok jemaat yang mengadakan kebaktiannya sendiri-sendiri. Pada 1921 dibuka gereja pertama di Solo yang bertempat di kampung Margoyudan yang dapat menampung lebih dari 300 jemaat. Usaha pekabaran Injil tidak hanya menyentuh kalangan rakyat biasa tetapi juga bangsawan. Pendeta utusan Gereja Gereformeerd Belanda di Solo Pdt. Dr. H.A. van Andel beserta istrinya menjalin hubungan baik dengan para bangsawan terutama dari Mangkunegaran. Banyak bangsawan Mangkunegaran yang bersimpati kepada agama Kristen meskipun tidak serta-merta membuat mereka masuk Kristen. ${ }^{25}$

Memasuki dekade 1930-an jemaat Kristen di Solo semakin berkembang secara kuantitas. Oleh karena jumlah warga jemaat bertambah banyak, gereja di Solo pun bertambah. Untuk warga jemaat dari etnis Jawa didirikan Gereja Manahan atau Tumenggungan di sebelah barat kota dan Gereja Danukusuman di selatan kota. Gereja Manahan yang dapat menampung sekitar 250 orang diresmikan pembukaannya tanggal 16 Oktober 1931. Pada masa ini pula untuk pertama kalinya ada orang Jawa ditahbiskan sebagai pendeta di Solo yaitu M. Soemponohardjo yang melayani Jemaat Margoyudan dan M. Atmowidjono yang melayani Jemaat Manahan. Soemponohardjo ditahbiskan pada 1932 sementara Atmowidjono ditahbiskan pada 1937. ${ }^{26}$

Secara umum sampai dengan akhir masa kolonial terjadi pertumbuhan penganut Kristen Protestan yang pesat di Solo dan sekitarnya. Sedikit-banyak ini adalah buah dari usaha pekabaran Injil oleh zending lewat sarana layanan pendidikan dan kesehatan. Sejarawan Karel Steenbrink menyebutkan pertumbuhan serupa juga dialami Gereja Katolik. Statistik tahun 1939 menunjukkan ada 4.349 penganut Katolik di Solo. Jumlah orang Katolik dari etnis Jawa sudah melebihi penganut Katolik dari kalangan Eropa dan Indo. Orang Katolik Jawa tercatat berjumlah 2.279 orang sedangkan orang Katolik Eropa dan Indo berjumlah 2.070 orang. ${ }^{27}$

\section{Misi Kristen di Solo Masa Jepang hingga Kemerdekaan Indonesia}

Masa penjajahan Jepang adalah periode yang sulit bagi umat Kristen di Indonesia, tak terkecuali di Pulau Jawa, karena pada masa ini banyak pekerja zending yang berkebangsaan Belanda ditahan oleh Jepang. Selain itu kekacauan yang terjadi menyusul jatuhnya pemerintahan kolonial Belanda juga membuat umat Kristen menjadi korban. Di Solo misalnya, tak lama setelah bala tentara Jepang datang terjadi kerusuhan yang menyasar orang-orang yang dianggap sebagai kaki-tangan Belanda meliputi orang-orang Indo, Cina, dan Kristen pribumi. Daerah pemukiman orang Eropa dan gereja orang Cina di Sangkrah dijarah. ${ }^{28}$ Oleh karena para pendeta berkebangsaan Belanda telah ditahan, hanya tersisa 1 orang pendeta pribumi di Solo yaitu Ds. Atmowidjono yang berkedudukan di gereja Manahan. ${ }^{29}$ Kesulitan yang sama juga 
dialami Misi Katolik. Sekolah-sekolah Kanisius di Solo diambil alih tentara Jepang untuk dijadikan kantor atau markas tentara. Para pengasuh sekolah yang berkebangsaan Belanda termasuk pastor, bruder, dan suster diinternir. Baru pada 1943 sekolah-sekolah Katolik boleh beroperasi kembali. ${ }^{30}$

Berakhirnya masa penjajahan Jepang tidak berarti masa-masa krisis bagi umat Kristen di Solo khususnya jemaat GKD (Geredja Kristen Djawa) ${ }^{31}$ juga berakhir. Setelah proklamasi kemerdekaan Pdt. Atmowidjono sudah meninggal dunia dan kedudukannya diganti oleh Pdt. R.M. Soegimo Poerwowidagdo. Menurut laporan klasis Solo di hadapan sinode tanggal 30 Oktober 1946 jumlah guru Injil hanya tersisa 9 orang. Kebanyakan para guru Injil itu berhenti dari pekerjaannya karena jemaat tempat mereka bekerja tidak mampu mencukupi biaya hidup mereka. Selain itu persembahan bulanan dan mingguan juga minim. ${ }^{22}$ Dengan kondisi yang demikian terjadi penurunan jumlah umat Kristen Protestan dewasa di Keresidenan Surakarta dibanding masa sebelum perang dari hampir 5.000 orang pada 1939 menjadi 2.700 orang pada 1949.33

Sementara itu di Solo antara tahun 1945-1950 sekolah-sekolah Kanisius dipimpin oleh Pastor Poesposoeparto SJ. Meskipun ada di tengah situasi sulit sekolah-sekolah ini tetap mampu berkembang dengan baik. Terjadi peningkatan jumlah murid di sekolahsekolah Kanisius dari dari 9.726 orang pada 1945 menjadi 12.349 orang tahun 1950. Sekolah-sekolah Kanisius juga menunjukkan efektivitasnya sebagai sarana pekabaran Injil. Tahun 1945 jumlah murid yang telah dibaptis tercatat sebanyak 163 orang sementara pada 1950 jumlahnya naik menjadi 675 orang. ${ }^{34}$ Pada masa Perang Kemerdekaan ini pula ada seorang tentara yang kemudian menjadi Katolik dan belakangan ditahbiskan sebagai "pahlawan kota Solo" yaitu Letkol. Ignatius Slamet Riyadi. Ia dikenang karena memimpin serangan umum pasukan TNI yang berhasil mengusir NICA dan tentara Belanda serta menduduki kota Solo selama 4 hari dari tanggal 7-10 Agustus 1949.35 Keberhasilan ini menunjukkan kepada dunia bahwa Republik Indonesia yang diklaim telah kalah oleh Belanda ternyata masih eksis. Di kemudian hari nama Slamet Riyadi - yang gugur ketika ikut serta dalam operasi penumpasan pemberontakan RMS di Ambon Maluku - diabadikan sebagai nama sebuah jalan protokol di Solo.

Usai Perang Kemerdekaan GKD di Solo berbenah kembali. Pada 1951 Klasis Solo dari GKD terdiri dari 16 jemaat dengan 5.10o jiwa anggota, meliputi baik kota Solo sendiri maupun daerah-daerah lainnya di Keresidenan Surakarta. Pada tahun ini Klasis Solo memiliki 2 orang pendeta utusan yang terdiri dari 1 orang Jawa dan 1 orang Belanda. Dalam hal pemasyhuran Injil Klasis Solo bekerjasama dengan jemaat Delft dari GKN (Gereformeerde Kerk Nederland). Jemaat Delft menugaskan Pdt. G.D. Kuiper sebagai pendeta utusan. ${ }^{36}$

Sementara itu berakhirnya Perang Kemerdekaan menandai babak baru dalam proses dekolonisasi Indonesia. Hal ini berimbas pula pada Misi Katolik. Pada 1950, 90\% tenaga misi Katolik di Indonesia adalah orang Belanda. Agar tetap bisa berkarya di Indonesia banyak di antara mereka yang memutuskan menjadi warga negara Indonesia. Kebetulan pada 1949-1951 dibuka kesempatan bagi orang asing untuk menjadi warga negara Indonesia dengan cara yang sederhana. Akan tetapi situasi politik pasca-kolonial yang masih kuat diwarnai sentimen anti-Belanda mencegah lebih banyak lagi tenaga 
misi asal Belanda untuk berkarya di Indonesia. Pada bulan Juni 1952 Kementerian Agama menolak memberikan rekomendasi masuk bagi 500 orang misionaris Katolik berkebangsaan Belanda. Kemudian pada 1 Agustus 1959 pemerintah mengeluarkan peraturan yang melarang pengajar dari luar negeri mengajar di sekolah-sekolah Indonesia. Ini secara langsung berdampak pada sekolah-sekolah Katolik - termasuk sekolah-sekolah Kanisius di Solo - mengingat banyak tenaga pengajar di sekolahsekolah ini adalah bruder dan suster berkebangsaan asing khususnya Belanda. ${ }^{37}$

Memasuki dasawarsa 1960-an situasi politik yang "revolusioner" ikut membawa pengaruh bagi aktivitas gereja-gereja Protestan. Hubungan Indonesia-Belanda yang memanas terkait sengketa Irian Barat berdampak pada dideportasinya warga negara Belanda yang berada di Indonesia, termasuk juga para pekerja gereja. Di GKD misalnya pada akhir tahun 1960 tercatat hanya tinggal 16-17 tenaga kerja asal Belanda yang tersisa, padahal pada 1957 tercatat ada kurang lebih 50 orang. Dengan berkurangnya jumlah pekerja gereja asal Belanda sudah barang tentu sedikit-banyak menghambat aktivitas gereja. Sebagai contoh ada pekerja asal Belanda yang semula bertugas mengajar dipindahtugaskan untuk berkonsentrasi mengurus soal keuangan. $3^{8}$

Sekalipun demikian usaha pekabaran Injil terus berjalan dengan memerhatikan segmen-segmen tertentu, misalnya wanita. Dalam hal pekabaran Injil kepada wanita, di lingkungan GKD upaya ini bermula di Solo dengan kedatangan tenaga wanita pekabaran Injil dari Belanda. Mereka keluar masuk kampung untuk memberitakan Injil kepada kaum wanita dan memberikan pelatihan-pelatihan kepada wanita jemaat GKD agar mampu memberitakan Injil pula. ${ }^{39}$

Ketegangan politik pada dekade 1960-an memuncak dengan pecahnya peristiwa G-30-S tahun 1965. Kota Solo sebagai basis PKI diwarnai ketegangan. Di tengah situasi mencekam ini kegiatan gereja terus berjalan. Setelah masuknya pasukan RPKAD situasi berangsur-angsur normal kembali. Pihak militer mengerahkan kelompok-kelompok paramiliter non-komunis untuk ikut mengendalikan keamanan di Solo. Termasuk di antara kelompok paramiliter yang dikerahkan adalah GAMKI (Gerakan Angkatan Muda Kristen Indonesia) bersama-sama dengan Ansor, Pemuda Marhaen, dan Pemuda Katolik. Menyikapi G-30-S jemaat-jemaat GKD Klasis Solo Barat dan Solo Timur mengambil keputusan untuk mengeluarkan anggota jemaat yang terbukti tersangkut gerakan tersebut dan yang menjadi anggota PKI dari GKD. Sanksi yang sama juga diberlakukan bagi anggota jemaat GKD yang diamankan oleh pihak militer. Di beberapa daerah sekitar Solo sendiri seperti Delanggu, Prambanan, dan Boyolali ada anggota jemaat GKD yang terlibat Gestapu (G-30-S). Bagi anggota jemaat GKD yang dikeluarkan dapat diterima kembali sebagai anggota jemaat jika mengakui kesalahan di hadapan sidang jemaat setelah mengadakan pembicaraan-pembicaraan rohani yang mendalam dengan Majelis Jemaat. Akibat pembersihan unsur-unsur PKI, SMP Kristen di Eromoko Wonogiri macet karena banyak gurunya yang ditahan sehubungan dengan keterlibatan mereka dalam PGRI N.V. (Non-Vakcentraal), organisasi guru yang berafliasi dengan PKI. ${ }^{\circ}$ Adapun dari pihak Gereja Katolik pada 22 Oktober 1965 Keuskupan Agung Semarang -yang wilayahnya juga mencakup Solo dan sekitarnya- mengeluarkan Surat Gembala yang ditandatangani Vicar General (Sekretaris Umum) P. Carri, SJ menyerukan kepada umat Katolik untuk menunjukkan semangat Pro Ecclesia et Patria ("Untuk Gereja dan Tanah Air") dengan membela dasar negara Pancasila yang 
melindungi keberagaman dan didasarkan atas keyakinan kepada Tuhan dari rongrongan kaum komunis. Selanjutnya pada 6 November 1965 Keuskupan Agung Semarang kembali mengeluarkan Surat Gembala yang isinya melarang para imam dan anggota ordo religius ikut serta dalam screening terhadap para terduga PKI yang dilakukan pihak militer. Terakhir tanggal 6 Januari 1966 Keuskupan Agung Semarang mengeluarkan Surat Gembala yang ditandatangani langsung Uskup Agung Justinus Darmojuwono berisi seruan kepada kaum awam Katolik untuk mendukung screening yang dilakukan militer terhadap para terduga PKI dengan syarat tidak melakukan kekerasan terhadap mereka. ${ }^{41}$

Di luar situasi yang genting tersebut baik GKD maupun Gereja Katolik mendapat lahan yang terbuka luas bagi pekabaran Injil seiring dengan diperkenankannya indoktrinasi bagi para tahanan militer yang disangkakan terlibat PKI. Kesempatan bagi pekabaran Injil di Solo semakin dipermudah mengingat Pejabat Walikota Solo yang menggantikan Utomo Ramelan - Walikota Solo yang berasal dari PKI - adalah Letkol Th. J. Soemantha yang seorang Katolik..$^{22}$ Di Solo aparat mendatangkan para pemuka agama - termasuk Kristen - untuk memberikan penerangan tentang agama pada para tahanan yang dikumpulkan di Pagelaran Keraton Kasunanan. ${ }^{43}$

\section{Persaingan dan Kecurigaan (Akhir 1960-an sampai 1990-an)}

Sebagai bagian dari upayanya menghancurkan komunisme, pemerintah Orde Baru membuka lebar-lebar kesempatan bagi kaum Muslim santri dan kalangan Kristen untuk "mengagamakan" orang-orang abangan yang dianggap "tidak beragama”. Dalam kaitannya dengan proyek modernisasi Orde Baru proses "pengagamaan" kaum abangan dipandang sejalan dengan modernisasi karena "pengagamaan” akan mengikis tradisi kaum abangan yang dianggap penuh dengan mitos, takhayul dan klenik. Pendeknya segala hal yang dipandang tidak sejalan dengan modernitas.

Kaum abangan di Surakarta dan di daerah-daerah lainnya dijadikan sebagai obyek dakwah kalangan Muslim santri dan obyek pekabaran Injil kaum Kristen dengan dukungan pemerintah. Di sini kita bisa mengatakan bahwa terjadi kontestasi antara kaum Muslim (baca: santri) dengan Kristen dalam "memperebutkan" kaum abangan. Kontestasi itu terjadi dalam panggung modernisasi yang diprakarsai pemerintah Orde Baru. Oleh karena itu wajar jika kemudian terjadi "perebutan” atas produk-produk sekaligus penanda modernitas antara pihak Muslim dan Kristen guna "memenangkan jiwa" kaum abangan tersebut.

Salah satu di antara produk dan penanda modernitas adalah sekolah. Tidak heran bila dalam konteks "pembangunan" atau modernisasi yang digalakkan pemerintah Orde Baru perluasan pendidikan - yang disama-sebangunkan dengan persekolahan atau lembaga pendidikan formal - menjadi hal yang penting. Selain pemerintah, lembaga-lembaga swasta - termasuk yang bercorak agama - juga turut berperan menyediakan layanan pendidikan. Di lapangan ini tampak bahwa lembagalembaga Islam maupun Kristen berlomba membuka institusi pendidikan formal. 
Tabel 1

Perbandingan Jumlah Sekolah Umum Tingkat Menengah dan Tinggi

Bercorak Islam \& Kristen (Katolik \& Protestan) di Surakarta, 1969-1970

\begin{tabular}{|c|c|c|c|c|c|c|}
\hline \multirow{2}{*}{ Tahun } & \multicolumn{3}{|c|}{ Islam } & \multicolumn{3}{c|}{ Kristen } \\
\cline { 2 - 7 } & SLTP & SMTA & PT & SLTP & SMTA & PT \\
\hline 1969 & 9 & 10 & 4 & 12 & 10 & 1 \\
\hline 1970 & 9 & 15 & 5 & 17 & 11 & 1 \\
\hline
\end{tabular}

Sumber: Diolah dari Sala dalam Angka tahun 1969 \& 1970

Melihat tabel di atas tampak adanya persaingan antara lembaga-lembaga Islam dan Kristen dalam menyediakan layanan pendidikan. Secara keseluruhan lembaga pendidikan Islam dan Kristen untuk jenjang pendidikan menengah dan tinggi pada 1970 sama-sama berjumlah 29 buah. Dengan demikian dalam kurun waktu 1969-1970 baik lembaga pendidikan Islam maupun Kristen di Surakarta mengalami kenaikan secara kuantitas. Jumlah lembaga pendidikan Islam maupun Kristen ini sama-sama naik sebesar kurang lebih $25 \%$. Di sini kita bisa melihat persaingan yang cukup ketat antara lembaga-lembaga Islam dan Kristen di Surakarta dalam menyediakan layanan pendidikan.

Persaingan dalam menyediakan layanan pendidikan tentu terkait erat dengan arti penting lembaga pendidikan dalam menanamkan nilai-nilai dan membentuk karakter peserta didik. Terkait dengan itu ada persepsi kuat di kalangan Muslim bahwa sekolah-sekolah Kristen adalah sarana untuk mengkristenkan kaum Muslim mengingat banyak murid sekolah-sekolah tersebut yang berasal dari keluarga Muslim. ${ }^{44}$ Secara historis keberadaan sekolah-sekolah Kristen memang penting artinya dalam proses pekabaran Injil di berbagai tempat, tak terkecuali di Surakarta. Tidak sedikit konversi secara individu terjadi pada mereka yang belajar di sekolah Kristen. 45 Namun karena ketiadaan data sulit diverifikasi seberapa jauh signifikansi sekolah-sekolah Kristen bagi terjadinya konversi para pelajar Muslim di sekolah-sekolah tersebut ke Kristen. Terlepas dari itu yang jelas keberadaan sekolah-sekolah Kristen mendorong kalangan Muslim mengimbanginya dengan mendirikan sekolah-sekolah Islam.

Terjadinya konversi tentu ikut memengaruhi dinamika perimbangan jumlah pemeluk Islam dan Kristen di Surakarta. Bagaimana perimbangan jumlah pemeluk kedua agama ini pada masa Orde Baru terlihat dalam tabel berikut:

Tabel 2

Perbandingan Jumlah Penduduk Muslim \& Kristen di Surakarta, 1970-1990

\begin{tabular}{|c|c|c|c|}
\hline Tahun & Islam & Kristen & Jumlah Penduduk \\
\hline 1970 & 286.928 & 78.991 & 449.128 \\
\hline 1980 & 336.084 & 112.257 & 459.257 \\
\hline 1990 & 379.386 & 129.164 & 516.967 \\
\hline
\end{tabular}

Sumber: Sala dalam Angka tahun 1970 dan Statistik Tahunan Kotamadya Surakarta tahun 1975-1995. 
Menilik data di atas terlihat bahwa baik pemeluk Islam maupun Kristen samasama mengalami peningkatan secara kuantitas. Akan tetapi menarik dilihat bahwa naiknya jumlah pemeluk Kristen di Surakarta seolah membenarkan klaim kalangan Muslim bahwa telah terjadi Misi Kristen yang menyasar umat Islam sebagai obyek. Terlebih bila dikaitkan dengan fakta bahwa gereja-gereja memandang pekabaran Injil sebagai kewajiban yang tidak bisa ditinggalkan dan mereka mengelola aktivitas ini secara serius. Walaupun demikian tentu harus diingat bahwa kenaikan jumlah pemeluk Kristen di Surakarta sepanjang masa Orde Baru bisa pula didorong oleh faktor natalitas dan migrasi. Mengingat ketiadaan data sulit untuk membuktikan klaim bahwa kenaikan jumlah penduduk Kristen di Surakarta terjadi terutama karena konversi yang terjadi sebagai hasil dari usaha penginjilan - sekalipun adanya konversi sebagai buah pekabaran Injil memang diakui sendiri oleh pihak Kristen. Di sisi lain perlu pula dicatat bahwa penduduk Muslim - setidaknya yang secara formal menyatakan dirinya beragama Islam - masih merupakan mayoritas di Surakarta dan jumlahnya secara umum juga terus bertambah. Bertambahnya jumlah pemeluk agama membawa konsekuensi logis bertambahnya jumlah rumah ibadah guna memenuhi kebutuhan para pemeluk agama untuk beribadah. Bagaimana pertumbuhan rumah ibadah Islam dan Kristen dapat dilihat sebagai berikut:

Tabel 3

Perbandingan Jumlah Masjid dan Gereja di Surakarta, 1970-1997

\begin{tabular}{|c|c|c|}
\hline Tahun & Masjid & Gereja \\
\hline 1970 & 69 & 34 \\
\hline 1980 & 149 & 76 \\
\hline 1990 & 241 & 117 \\
\hline 1991 & 252 & 120 \\
\hline 1997 & 353 & 141 \\
\hline
\end{tabular}

Sumber: Sala dalam Angka tahun 1969-1970 dan Statistik Tahunan Kotamadya Surakarta 1975-1995; dan Kotamadya Surakarta dalam Angka tahun 1996-1997.

Berdasarkan tabel di atas kita bisa melihat terjadinya pertumbuhan masjid maupun gereja yang boleh dibilang "fantastis" di Surakarta selama periode Orde Baru. Pertumbuhan masjid dan gereja yang sangat pesat di Surakarta pada masa Orde Baru ini akan menjadi semakin "fantastis" jika kita bandingkan dengan jumlah masjid dan gereja pada masa sebelum Orde Baru. Menurut data Kantor Urusan Agama Kota Besar Surakarta tahun 1951 tercatat jumlah masjid di kota ini sebanyak 58 buah sedangkan gereja hanya berjumlah 13 buah, terdiri dari 11 gereja Protestan dan 2 gereja Katolik. Empat dekade kemudian (1991) tercatat jumlah masjid sebanyak 252 buah atau naik sebesar lebih dari 400\%. Kenaikan jumlah gereja lebih luar biasa lagi, dari hanya 13 buah pada 1951 menjadi 120 pada 1991. Dengan kata lain terjadi kenaikan sebesar lebih dari $900 \%$ dalam kurun waktu empat dasawarsa. Data-data kuantitatif di atas bisa menjadi indikasi bahwa proses "pengagamaan" berlangsung dengan sangat intensif di Surakarta. Dalam kaitannya dengan hal tersebut, keberadaan masjid ataupun gereja dapat dilihat baik sebagai bagian dari proses "pengagamaan" ataupun hasil dari proses "pengagamaan”. 
Sementara itu berlangsungnya gelombang konversi massal ke Kristen pasca 1965 memang mencemaskan kalangan Islam, terlebih banyak di antara para penyintas itu adalah eks-anggota maupun simpatisan PKI yang notabene adalah musuh politik golongan Islam. Ada kekhawatiran bahwa orang-orang eks-PKI berlindung di gereja untuk meneruskan agendanya menghantam Islam politik mengingat ada kepentingan yang sama dengan kalangan Kristen untuk melawan Islam politik. ${ }^{46}$ Selain itu, ada pula kekhawatiran jika gelombang penyintas ini tidak segera ditanggapi secara serius bukan tidak mungkin dalam jangka waktu beberapa dekade berikutnya umat Islam akan menjadi minoritas. Oleh karena itu pekabaran Injil yang dilakukan pihak Kristen mendapat perhatian tersendiri dari kalangan Islam di Surakarta. Muncul seruan agar umat Islam memikirkan dan menjalankan langkah-langkah yang efektif untuk menghambat laju Misi Kristen. ${ }^{47}$

Kekhawatiran terhadap Misi Kristen relatif mereda pada dasawarsa 1990-an ketika rezim Orde Baru memasuki masa "bulan madu" dengan kalangan Islam yang ditandai salah satunya dengan pendirian ICMI (Ikatan Cendekiawan Muslim seIndonesia) pada akhir tahun 1990. ICMI segera menjadi pemain yang dominan dalam arena politik dan birokrasi tidak hanya di pusat tetapi juga sampai ke daerah-daerah. Di Surakarta sendiri kehadiran ICMI turut membawa dampak dalam birokrasi pemerintahan daerah. Menurut penuturan seorang mantan pengurus ICMI Surakarta hampir semua birokrat yang beragama Islam di Surakarta ketika itu dari mulai walikota sampai lurah berbondong-bondong menjadi anggota ICMI. ${ }^{8}$ Masih kentalnya budaya patronase tampaknya mendorong gejala ini. Dukungan elit penguasa di tingkat pusat terhadap ICMI ditangkap oleh pejabat di daerah sebagai isyarat untuk ikut serta dalam organisasi ini atau isyarat agar mereka bergabung dengannya jika tidak ingin posisinya di birokrasi tergusur. Fenomena ini disebut-sebut mengalienasikan para birokrat yang beragama Kristen. Kabarnya posisi-posisi strategis dalam birokrasi pemerintahan daerah dikuasai oleh mereka yang berafiliasi dengan ICMI. ${ }^{49}$ Adapun para birokrat Kristen tidak mendapat kesempatan untuk menduduki jabatan-jabatan strategis meskipun mereka memiliki kapasitas yang memadai. Kemampuan personal tidak menjadi satu-satunya pertimbangan, faktor agama dan afiliasi organisasi juga menjadi pertimbangan yang bahkan mungkin lebih penting dalam pengisian jabatan..$^{0}$

Bagi umat Kristen sendiri masa akhir Orde Baru pada dekade 1990-an dikenang sebagai masa-masa mulai maraknya intoleransi terhadap umat Kristen sebagaimana ditandai banyaknya kerusuhan yang menyasar gedung-gedung gereja dan bangunanbangunan lainnya milik umat Kristen. ${ }^{51}$ Akan tetapi hal ini tidak terjadi di Surakarta. Jikapun terjadi ketegangan maka itu hanya berlangsung di bawah permukaan dan tidak meletup menjadi kerusuhan atau konflik fisik. Di antara faktor yang dapat mencegah timbulnya konflik terbuka antara komunitas Muslim dan Kristen di kota ini adalah adanya hubungan kekeluargaan dan kekerabatan di antara warga yang berbeda agama. Di Surakarta bukan hal yang aneh jika di dalam satu rumah ataupun keluarga besar ada anggota keluarga yang Muslim dan ada yang Kristen..$^{2}$

Meskipun demikian bukan berarti tidak ada sama sekali kasus yang jika saja tidak segera ditangani bisa mengarah pada konflik antar umat beragama. Masalah pendirian gereja adalah kasus yang potensial memicu timbulnya konflik. Menurut hasil penelitian Mulyadi dan Soedarmono, pada sekitar tahun 1989-1990 sempat muncul protes dari 
mereka yang mengatasnamakan umat Islam Kelurahan Jagalan ketika sekelompok umat Kristen dari Gereja Bethany hendak mendirikan gedung gereja di perkampungan sebelah timur Kerkhoff (kuburan Belanda). Pada 1990 pendirian sebuah gereja - juga oleh jemaat Gereja Bethany - di sebelah barat kampus STSI (Sekolah Tinggi Seni Indonesia) Kentingan Jebres juga sempat mendapat protes dari sekelompok umat Islam. ${ }^{53}$ Hanya saja kasus ini dapat dilokalisir sehingga tidak menimbulkan konflik yang lebih besar.

\section{PENUTUP}

Aktivisme Islam dan misi Kristen bukan suatu fenomena baru di Solo, sebagai sebuah proses yang berjalan paralel keduanya sudah berlangsung sejak era kolonial. Satu hal yang perlu dicatat baik aktivisme Islam maupun misi Kristen di kota ini sejak masa kolonial tidak bisa dilepaskan dari konteks modernisasi. Dalam kasus aktivisme Islam, berdirinya organisasi-organisasi seperti SDI/SI dan SATV/Muhammadiyah mencerminkan akomodasi yang dilakukan kaum Muslim santri di Solo atas produkproduk modernitas - dalam hal ini organisasi - untuk mengartikulasikan dan mengaktualisasikan cita-cita Islam. Sementara dalam kasus misi Kristen, sejak awal lembaga zending dan misi telah hadir sebagai agen modernisasi lewat sekolah-sekolah dan rumah sakit yang didirikannya.

Sementara itu peristiwa 1965 dan perubahan sosial di Solo pada masa Orde Baru adalah konteks lain yang penting dilihat untuk memahami aktivisme Islam dan misi Kristen di kota ini. Pengidentikan "ketidakberagamaan" dengan komunisme membuka lahan yang terbuka lebar bagi proses "pengagamaan” segmen masyarakat yang dianggap "tidak -atau kurang- beragama" dan lahan ini digarap oleh para agen proselitisasi agama baik dari kalangan Muslim maupun Kristen. Pada masa Orde Baru proses Islamisasi maupun Kristenisasi berlangsung intensif. Bisa dikatakan terjadi persaingan antara dakwah dan pekabaran Injil di kota ini. Persaingan ini menjadi latar bagi timbulnya sentimen-sentimen anti-Kristen di sebagian kalangan Islam di kota Solo.

\section{REFERENSI}

Al Chaidar. (1999). Pemikiran Politik Proklamator Negara Islam Indonesia S.M. Kartosoewirjo. Jakarta: Darul Falah.

Aritonang, Jan S. \& Karel Steenbrink (eds). (2008). A History of Christianity in Indonesia. Studies in Christian Mission. Leiden \& Boston: Brill.

Boelaars, Huub J.W.M. (2005). Indonesianisasi: Dari Gereja Katolik di Indonesia menjadi Gereja Katolik Indonesia. Yogyakarta: Kanisius.

Dijk, C. van. (1987). Darul Islam: Sebuah Pemberontakan. Jakarta: Pustaka Utama Grafiti.

Dirdjosanjoto, Pradjarta, et al. (ed). (20o8). Sumber-sumber tentang Sejarah Gereja Kristen Jawa, 1896-1980. Salatiga: Pusat Arsip Sinode GKJ.

Faqih, Markhaban. (1988). Golongan Santri dan Pemberontakan Batalyon 426 di Klaten. Skripsi. Jurusan Ilmu Sejarah Fakultas Sastra UGM. 
Hefner, Robert W. (1993). Islam, State, and Civil Society: ICMI and the Struggle for the Indonesian Middle Class. Indonesia, 56.

Khadiq. (2004). Islam di Tengah Dinamika Sosial Surakarta Awal Abad XX, 1916-1942. Tesis. Program Pascasarjana FIB UGM.

Klinken, Gerry van. (2007). Communal Violence and Democratization in Indonesia: Small Town Wars. New York: Routledge.

Kuntowijoyo. (2004). Raja, Priayi, dan Kawula: Surakarta 1900-1915. Yogyakarta: Ombak.

Liddle, R. William. (1996). The Islamic Turn in Indonesia: a Political Explanation. The Journal of Asian Studies, 55(3).

Majalah Adil edisi November 1974, No. 4 dan Januari 1975 No. 8.

Mulyadi, M. Hari \& Soedarmono. (1999). Runtuhnya Kekuasaan "Kraton Alit” (Studi Radikalisasi Sosial "Wong Sala” dan Kerusuhan Mei 1998 di Surakarta. Surakarta: Lembaga Penelitian Teknologi Pedesaan.

Ricklefs, M.C. (2012). Islamization and Its Opponents in Java. C. 1930-Present. Singapore: NUS Press.

Shiraishi, Takashi. (1997). Zaman Bergerak: Radikalisme Rakyat di Jawa, 1912-1926 (Hilmar Farid, trans.). Jakarta: Pustaka Utama Grafiti.

Steenbrink, Karel. (2007). Catholics in Indonesia, 1808-1942: The Spectacular Growth of a Self-Confident Minority, 1903-1942. Leiden: KITLV.

Tashadi, et al. (1997). Sejarah Perjuangan Hizbullah Sabilillah Divisi Sunan Bonang. Surakarta: Yayasan Bhakti Utama.

Wahyudi, Sarjana Sigit. (2001). Ketika Sarbupri Mengguncang Pabrik Karung Delanggu 1948: Sebuah Studi Awal dari Pemberontakan PKI Madiun. Semarang: Bendera.

Wolterbeek, J.D. (1995). Babad Zending di Pulau Jawa. Yogyakarta: Taman Pustaka Kristen.

\footnotetext{
${ }^{1}$ http://jateng.tribunnews.com/2019/01/18/gelar-unjuk-rasa-ormas-islam-di-solo-minta-mozaik-mirip-salib-didepan-balai-kota-diubah diakses tanggal 28 Februari 2019 pukul 10:14 WIB.

2 https://www.merdeka.com/cek-fakta/jalan-depan-balai-kota-solo-dibilang-mirip-salib-ini-faktanya.html dan https://nasional.tempo.co/read/1166289/ornamen-mirip-salib-pemerintah-kota-surakarta-bertemuagamawan diakses tanggal 28 Februari 2019 pukul 10:18 WIB.

${ }^{3}$ https://www.bbc.com/indonesia/indonesia-46915107 diakses tanggal 28 Februari 2019 pukul 10:20 WIB.

${ }^{4}$ https://www.hidayatullah.com/berita/berita-dari-anda/read/2015/05/17/69791/acara-parade-tauhid-disolo-dihadiri-ratusan-ribu-peserta.html diakses tanggal 28 Februari 2019 pukul 10:22 WIB.

${ }^{5}$ https://foto.tempo.co/read/29186/kirab-paskah-bersama-solo-panggul-270-salib diakses tanggal 28 Februari 2019 pukul 10:22 WIB.

6 Takashi Shiraishi. (1997). Zaman Bergerak. Radikalisme Rakyat di Jawa 1912-1926 (Penerjemah Hilmar Farid) (Jakarta: Pustaka Utama Grafiti), hlm. 55.

${ }^{7}$ Ibid, hlm. 57.

${ }^{8}$ Khadiq, (2004), “Islam di Tengah Dinamika Sosial Surakarta Awal Abad XX 1916-1942”, Tesis, (Yogyakarta:

Program Pascasarjana FIB UGM), hIm. 142.

9 Ibid, hlm. 143.

10 Shiraishi (1997), hlm. 393.

${ }^{11}$ Darmo Kondho 1 April 1933 dalam Khadiq. 2004, hal. 266.
} 
12 Tashadi dkk, (1997), Sejarah Perjuangan Hizbullah Sabilillah Divisi Sunan Bonang (Surakarta: Yayasan Bhakti Utama), hlm. 31.

${ }^{13} \mathrm{lbid}, \mathrm{hlm} .34$.

${ }^{14}$ Baca Sarjana Sigit Wahyudi, (2001), Ketika Sarbupri Mengguncang Pabrik Karung Delanggu 1948: Sebuah Studi Awal dari Pemberontakan PKI Madiun, (Semarang: Bendera).

${ }^{15}$ Baca Markhaban Faqih, (1988), "Golongan Santri dan Pemberontakan Batalyon 426 di Klaten”, Skripsi, (Yogyakarta: Jurusan Ilmu Sejarah Fakultas Sastra UGM).

16 C. Van Dijk, (1987), Darul Islam: Sebuah Pemberontakan (Jakarta: Pustaka Utama Grafiti), hlm. 141 dan Al Chaidar, (1999), Pemikiran Politik Proklamator Negara Islam Indonesia S.M. Kartosoewirjo (Jakarta: Darul Falah), hlm. 132.

${ }^{17}$ M. Hari Mulyadi \& Soedarmono, (1999), Runtuhnya Kekuasaan "Kraton Alit" (Studi Radikalisasi Sosial "Wong Sala" dan Kerusuhan Mei 1998 di Surakarta) (Surakarta: Lembaga Penelitian Teknologi Pedesaan), hlm. 166.

${ }^{18}$ Wawancara dengan Bapak Solihan Mahdum Cahyana tanggal 19 Mei 2014 Kauman Kecamatan Pasar Kliwon Surakarta.

19 J.D. Wolterbeek, (1939), Babad Zending di Pulau Jawa (Edisi Bahasa Indonesia. Diterbitkan kembali tahun 1995) (Yogyakarta: Taman Pustaka Kristen), hlm. 198.

${ }^{20}$ Kuntowijoyo (2004), Raja, Priayi, dan Kawula: Surakarta 1900-1915 (Yogyakarta: Ombak), hlm. 38.

${ }^{21}$ Wolterbeek. 1939, hlm. 199 dan Ibid, hlm. 38

${ }^{22}$ Wolterbeek, (1939), hlm. 199.

${ }^{23}$ Mulyadi \& Soedarmono, (1999), hIm. 159-160.

${ }^{24} \mathrm{Ibid}, \mathrm{hlm} .160$.

25 Ibid, hal. 206-207.

${ }^{26}$ Wolterbeek. (1939), hlm. 236-237.

${ }^{27}$ Karel Steenbrink (2007), Catholics in Indonesia 1808-1942; The Spectacular Growth of a Self-Confident Minority 1903-1942, (Leiden: KITLV), hlm. 663.

${ }^{28}$ De Jong dalam Jan S. Aritonang \& Karel Steenbrink (ed), (2008), A History of Christianity in Indonesia.Studies in Christian Mission, (Leiden \& Boston: Brill), hlm. 685.

${ }^{29}$ R.P.S. Poerbowijogo, “Keadaan Djema'at di lingkoengan Synode Djawa-tengah di zaman Djepang Maart 1942-Aug. 1945" tertanggal Argasasra 14 Agustus 1946 dalam Pradjarta Dirdjosanjoto et.al. (ed), (2008), Sumber-sumber tentang Sejarah Gereja Kristen Jawa 1896-1980, (Salatiga: Pusat Arsip Sinode GKJ), hlm. 72-73.

${ }^{30}$ Mulyadi \& Soedarmono, (1999), hlm. 161.

${ }^{31}$ GKD adalah gereja yang terbentuk dari pendewasaan jemaat-jemaat Kristen Jawa binaan Zending Gereformeerde Belanda. Dikukuhkan dalam sinode pertamanya tahun 1931 (Lihat Dirdjosanjoto et.al. (ed). (2008), hlm. 28-32).

32 Wijoto Hardjotaroeno, "Laporan Deputat-deputat Jemaat di Sinode GKJ tahun 1947 di Purwokerto

(Banyumas)" dalam ibid, hlm.. 81.

${ }^{33}$ De Jong dalam Aritonang \& Steenbrink (ed), (2008), hlm. 685-686.

${ }^{34}$ Mulyadi \& Soedarmono, (1999), hlm. 161.

35 Ibid, hlm. 210-212.

36 "Laporan para visitator kepada Synode Geredja2 Kristen Djawa-Tengah III jang bersidang pada tgl. 24-28 September 1951 di Salatiga." dalam Dirdjosanjoto et.al (ed), (2008), hlm. 129-130.

${ }^{37}$ Huub J.W.M. Boelaars, (2005), Indonesianisasi. Dari Gereja Katolik di Indonesia Menjadi Gereja Katolik Indonesia (Yogyakarta: Kanisius), hlm. 127-129 \& 134.

38 "Notula rapat dinas gredjani; tertanggal Salatiga 30 Agustus 1960" dalam Dirdjosanjoto et.al (ed), (2008), hlm. 221.

39 Ibu Soetirah, “Pekabaran Indjil kepada wanita; tertanggal Magelang 10 Juli 1962" dalam ibid, hlm. 233.

40 "Notula rapat bersama antara Deputat-deputat Pelaksana, Deputat-deputat Pekabaran Indjil Klasis, dan Pengurus Badan2 Kristen dalam wilajah sinode Geredja2 Kristen Djawa; tertanggal Salatiga, 25 dan 26 Januari 1966" dalam ibid, hlm. 257.

${ }^{41} \mathrm{G}$. Budi Subanar dalam Aritonang \& Steenbrink (ed), (2008), hlm. 707. Dalam praktiknya tentu saja sulit untuk memastikan apakah seruan untuk tidak melakukan kekerasan terhadap para terduga PKI ini betul-betul ditaati oleh kaum awam Katolik. Terlebih tidak sedikit dari mereka yang juga anggota tentara.

42 "Notula rapat bersama antara Deputat-deputat Pelaksana, Deputat-deputat Pekabaran Indjil Klasis, dan Pengurus Badan2 Kristen dalam wilajah sinode Geredja2 Kristen Djawa; tertanggal Salatiga, 25 dan 26 Januari 1966" dalam Dirdjosanjoto et.al (ed), (2008), hlm. 257. 
${ }^{43}$ Wawancara dengan Pdt. (Emeritus) Edi Trimodoroempoko (mantan Pendeta Jemaat GKJ Margoyudan) tanggal 21 April 2015 di Gentan Colomadu Karanganyar.

${ }^{44}$ Lihat dalam M.C. Ricklefs, (2012), Islamization and Its Opponents in Java. C 1930-Present, (Singapore: NUS Press), hlm. 509-511.

${ }^{45}$ Lihat misalnya dalam Aritonang \& Steenbrink (ed), (2008), hlm. 698 \& 700.

${ }^{46}$ Adil tahun ke-43 (November 1974) no. 4, hlm. 4-5.

${ }^{47}$ Adil tahun ke-43 (Januari 1975) no. 8, hlm. 41.

${ }^{48}$ Wawancara dengan Bapak A.M. al-Aydrus (mantan pengurus ICMI dan Golkar Kotamadya Surakarta) tanggal 15 April 2015 di Kentingan Jebres Kecamatan Jebres.

${ }^{49}$ Tentang analisis yang berkembang di seputar pendirian ICMI dan kiprahnya lihat Robert W Hefner. "Islam, State, and Civil Society: ICMI and the Struggle for the Indonesian Middle Class" dalam Indonesia no. 56 (1993), hlm. 1-37 dan R. William Liddle, "The Islamic Turn in Indonesia: a Political Explanation" dalam The Journal of Asian Studies vol. 55 no. 3 (1996), hlm. 613-634.

${ }^{50}$ Fenomena naiknya birokrat Muslim dan tersingkirnya birokrat Kristen ini terjadi antara lain di Maluku dan Poso. Hal ini turut melatarbelakangi pecahnya kerusuhan komunal di kedua daerah tersebut pada masa Reformasi (Lihat Gerry van Klinken, (2007), Communal Violence and Democratization in Indonesia. Small Town Wars. (New York: Routledge), hlm. 78 \& 92-94).

${ }^{51}$ Lihat Aritonang, (2006), hlm. 463-478.

${ }^{52}$ Wawancara dengan Bapak Heri Subagyo (Takmir Masjid Inoe Potrojayan Serengan) tanggal 2 September 2014 di Serengan Kecamatan Serengan dan wawancara dengan Bapak Bambang Sriwiyadi (anggota Majelis Sinode GKJ) tanggal 20 April 2015 di Nusukan Banjarsari Surakarta.

${ }^{53}$ Mulyadi \& Soedarmono, (1999), hlm. 170. 